\title{
Endocrine features of polycystic ovary syndrome in a random population sample of 14-16 year old adolescents
}

\author{
M.H.A.van Hooff ${ }^{1,5}$, F.J.Voorhorst ${ }^{2}$, \\ M.B.H.Kaptein ${ }^{1}$, R.A.Hirasing ${ }^{3}$, C.Koppenaal ${ }^{4}$ and \\ J.Schoemaker ${ }^{1}$ \\ ${ }^{1}$ Research Institute for Endocrinology, Reproduction and \\ Metabolism, Division of Reproductive Endocrinology and Fertility, \\ Vrije Universiteit Medical Centre, De Boelelaan 1117, 1081 HV \\ Amsterdam, ${ }^{2}$ Department of Epidemiology and Medical Statistics, \\ Free University, Amsterdam, ${ }^{3}$ Netherlands Organization for Applied \\ Scientific Research (TNO), Division Public Health and Prevention, \\ Leiden and ${ }^{4}$ Department of Youth Health Care of the Public Health \\ Care Service Amstelland-de Meerlanden, Amstelveen, \\ The Netherlands \\ ${ }^{5}$ To whom correspondence should be addressed
}

Hospital based studies have shown that oligomenorrhoeic adolescents have high luteinizing hormone (LH) and androgen concentrations, endocrine signs of polycystic ovary syndrome (PCOS). The prevalence of these abnormalities in an unselected population of adolescents is not known. We determined LH, follicle stimulating hormone (FSH), androstenedione, testosterone, dehydroepiandrosterone sulphate (DHEAS), oestradiol and prolactin concentrations in unselected population samples of adolescents with oligomenorrhoea, secondary amenorrhoea and regular menstrual cycles. A total of 2248 white, west European adolescents, aged $15.3 \pm 0.6$ (mean \pm SD) years, participated. Blood was taken from 107 adolescents with regular menstrual cycles, 52 with oligomenorrhoea and four with secondary amenorrhoea. Oligomenorrhoeic adolescents had higher mean LH, androstenedione, testosterone, DHEAS and oestradiol concentrations compared with girls with regular menstrual cycles; $57 \%$ of the oligomenorrhoeic girls had LH or androgen concentrations above the 95th centile of adolescents with regular menstrual cycles. None of the 52 oligomenorrhoeic girls and only one of four girls with secondary amenorrhoea had a hypogonadotrophic endocrine pattern. The present study and available literature support the view that oligomenorrhoea in adolescents is not a stage in the physiological maturation of the hypothalamic pituitary-ovarian axis but an early sign of PCOS associated with subfertility. Physicians should consider endocrine evaluation before reassuring oligomenorrhoeic girls or prescribing oral contraceptives to these girls.

Key words: adolescents/follicle stimulating hormone/luteinizing hormone/polycystic ovary syndrome

\section{Introduction}

Studies on the endocrinology of menstrual cycle disorders during puberty are few and have all been performed in outpatient clinic populations (Emans et al., 1980; Singh, 1981; Moll and Rosenfield, 1983; Siegberg et al., 1986, 1987; Siegberg, 1987; Venturoli et al., 1987). Selection occurring at each stage of the referral process may generate patient samples that are quite different from those found in the general population (Fletcher et al., 1988; Sackett et al., 1991). Thus, selection bias may be involved in these outpatient clinic studies. The present study provides cross-sectional data on the endocrinology of menstrual cycle disorders from an unselected population of 14-16 year old adolescents, who participated in the first phase of the Puberty Onset Menstrual cycle abnormalities, a Prospective study (POMP study). We have estimated the prevalence of endocrine abnormalities compatible with polycystic ovary syndrome (PCOS) in adolescents with various menstrual cycle disorders. We investigate whether adolescents with these irregular menstrual cycles can be reassured that this will be transient, or whether endocrine evaluation should be advised and information should be given about a higher probability for subfertility in adult life.

\section{Materials and methods}

The methodology of the POMP study has been described in detail elsewhere (van Hooff et al., 1998a). In summary, ninth grade schoolgirls in a combined rural and urban region south of Amsterdam were asked to fill out a questionnaire on their menstrual cycle pattern during the last year. The definitions of the menstrual cycle patterns used are given in Table I. In total, 2705 questionnaires were distributed and $2480(92 \%)$ were completed. The mean age of the respondents was $15.6 \pm 0.6(\mathrm{SD})$ years, range $14-17$.

Girls with oligomenorrhoea, secondary amenorrhoea or polymenorrhoea were all invited to participate in the second phase of the study, which entailed physical examination and venepuncture. For every girl with oligomenorrhoea or secondary amenorrhoea who agreed to venepuncture (61 of 96, 64\%), two girls with regular menstrual cycles were enrolled in the control group. Girls with regular menstrual cycles who were interviewed following the index person were asked to participate until two controls were included.

In the original protocol, it was decided not to use girls with irregular menstrual cycles for venepuncture because we expected a collection of heterogeneous menstrual cycle patterns in this group with the majority of girls only shortly after menarche. As $\sim 10 \%$ of all girls had irregular menstrual cycles in the first part of the study, we concluded that information about this group might be important for the interpretation of the study. So, in the second part of the study girls with irregular menstrual cycles were invited to participate, and 83 girls did so.

Oral contraceptive users $(n=247)$ and those who had not reached menarche $(n=133)$ were excluded. Girls who had reached menarche within the previous 6 months $(n=128)$ were excluded because this time span is too short to determine a menstrual cycle pattern. 
Table I. Definitions of menstrual cycle patterns

\begin{tabular}{|c|c|}
\hline Pre-menarche & No menarche and still before 16th birthday \\
\hline$<6$ months post-menarche & $\begin{array}{l}\text { Menarche less than } 6 \text { months before } \\
\text { participation in the study }\end{array}$ \\
\hline Primary amenorrhoea & $\begin{array}{l}\text { Menarche not established and after 16th } \\
\text { birthday }\end{array}$ \\
\hline Secondary amenorrhoea & $\begin{array}{l}\text { The absence of menstruation for } 180 \text { days or } \\
\text { more }\end{array}$ \\
\hline Oligomenorrhoea & $\begin{array}{l}\text { Average length of the menstrual cycle } \\
\text { between } 42 \text { and } 180 \text { days }\end{array}$ \\
\hline Polymenorrhoea & $\begin{array}{l}\text { Average length of the menstrual cycle } 21 \text { days } \\
\text { or less }\end{array}$ \\
\hline Regular menstrual cycles & $\begin{array}{l}\text { Average length of the menstrual cycle } \\
\text { between } 22 \text { and } 41 \text { days. Either none or a } \\
\text { maximum of } 1 \text { menstrual cycle with a length } \\
<22 \text { or }>41 \text { days during the past year }\end{array}$ \\
\hline Irregular menstrual cycles & $\begin{array}{l}\text { Average length of the menstrual cycle } \\
\text { between } 22 \text { and } 41 \text { days. Two or more } \\
\text { menstrual cycles with a length }<22 \text { or }>41 \\
\text { days during the past year }\end{array}$ \\
\hline Oral contraceptive use & $\begin{array}{l}\text { Use of oral contraceptives for contraception, } \\
\text { irregular menstrual cycles, dysmenorrhoea or } \\
\text { acne }\end{array}$ \\
\hline
\end{tabular}

Participants using hormonal medication other than oral contraceptives or insulin $(n=15)$, girls of whom one or both parents was not of west European descent $(n=207)$ and girls whose questionnaires were incomplete $(n=10)$ were also excluded.

\section{Physical examination}

Weight was measured to the nearest $0.5 \mathrm{~kg}$ using a mobile spring balance (Seca, Hamburg, Germany) and height to the nearest $0.5 \mathrm{~cm}$ using a mobile measuring rod (Microtoise, Stanley mabo, Poissy, France). Waist circumference was measured to the nearest $0.5 \mathrm{~cm}$ with a plastic tape at the smallest frontal waist diameter, usually at the level of the umbilicus. Hip circumference was measured at the broadest part of the lower body, usually at the level of the trochanters (Westrate et al., 1989). Pubarche and thelarche were scored according to the stages described (Tanner, 1962; Roede van Wieringen, 1985). Body hair grading was assessed according to the Ferriman and Gallwey score (Ferriman and Gallwey, 1961). Abnormal body hair was defined as a Ferriman and Gallwey score of $\geqslant 1$, hirsutism as a Ferriman and Gallwey score of $\geqslant 8$. Acne was assessed according to the Plewig and Kligman score (Plewig and Kligman, 1975). Acne was defined as a Plewig and Kligman score of $\geqslant 1$, serious acne as a Plewig and Kligman score $\geqslant 2$.

\section{Blood sampling}

Blood samples were taken from a forearm vein by the venoject system, usually at school, between 1200 and 1700 h. In girls with polymenorrhoea, regular or irregular menstrual cycles the blood samples were taken between the first and the 10th day of the menstrual cycle. To exclude influence of the midcycle luteinizing hormone (LH) peak, the blood samples from girls in these groups should have been taken at least 18 days before the next menstruation. In the girls with secondary amenorrhoea, blood samples were not timed. In oligomenorrhoeic girls, the blood sample was taken during the specific oligomenorrhoeic phase (SOP) defined as the time span between 2 weeks after the first day of a period and at least 3 weeks before the next period. This procedure excludes the possible influence of periovulatory changes and post-ovulatory progesterone production on $\mathrm{LH}$ and androgen concentrations, which may extend into the follicular phase of the next menstrual cycle. If this happens, lower LH and androgen concentrations result in the first 2 weeks after this menstruation (Minakami et al., 1988; van Hooff et al., 1998b). LH, androstenedione, testosterone and oestradiol concentrations during the SOP are known to be analogous to those in normogonadotrophic amenorrhoea (van Hooff et al., 1998b). The majority of women in the latter group were PCOS patients.

\section{Hormone assays}

Plasma LH and follicle stimulating hormone (FSH) concentrations were determined by immunofluorometric assays (Amerlite, Amersham UK). For the LH assay the lower limit of detection was $0.3 \mathrm{IU} / \mathrm{l}$. The intra-assay coefficients of variation (CV) were $5 \%$ at the level of $10 \mathrm{IU} / 1$ and $3 \%$ at levels of $20 \mathrm{IU} / 1$ and $40 \mathrm{IU} / 1$. The inter-assay CV was $10 \%$ at the level of $2 \mathrm{IU} / 1$ and $6 \%$ at the level of $40 \mathrm{IU} / 1$. For the FSH assay, the lower limit of detection was 0.5 IU/l. The intraassay CV was $6 \%$ at the level of $5 \mathrm{IU} / 1$ and $5 \%$ at levels of $15 \mathrm{IU} / \mathrm{l}$ and $40 \mathrm{IU} / \mathrm{l}$. The interassay $\mathrm{CV}$ was $9 \%$ at the level of $3 \mathrm{IU} / \mathrm{l}$ and $5 \%$ at the level of $35 \mathrm{IU} / \mathrm{l}$. Prolactin concentrations were measured by an immunoradiometric-assay (Medgenix Diagnostics, Fleurus Belgium) with a lower limit of detection of 0.05 IU/l. The intra-assay CV was $4 \%$ at the level of $0.25 \mathrm{IU} / 1$ and $6 \%$ at a level of $1.0 \mathrm{IU} / \mathrm{l}$. The interassay $\mathrm{CV}$ was $9 \%$ at the level of $0.15 \mathrm{IU} / 1$ and $7 \%$ at the levels of $1.0 \mathrm{IU} / 1$ and $2.0 \mathrm{IU} / \mathrm{l}$. Oestradiol concentrations were measured by means of a radioimmunoassay (Estradiol-2, Sorin Biomedica, Saluggia, Italy). The detection limit was $37 \mathrm{pmol} / \mathrm{l}$. The intra-assay CV was $4 \%$ at the level of $110 \mathrm{pmol} / \mathrm{l}$ and $5 \%$ at the level of $1000 \mathrm{pmol} / \mathrm{l}$, the interassay $\mathrm{CV}$ was $11 \%$ at the level of $70 \mathrm{pmol} / \mathrm{l}$ and $10 \%$ at the level of $400 \mathrm{pmol} / \mathrm{l}$. Serum androstenedione and dehydroepiandrosterone sulphate (DHEAS) were determined by using a radioimmunoassay (Coat a Count, DPC, Los Angeles USA). For the androstenedione assay, the lower limit of detection was $0.4 \mathrm{nmol} / \mathrm{l}$. The intra-assay $\mathrm{CV}$ was $5 \%$ at the level of $1 \mathrm{nmol} / \mathrm{l}$ and $8 \%$ at the level of $3 \mathrm{nmol} / \mathrm{l}$. The interassay $\mathrm{CV}$ was $11 \%$ at the level of $3 \mathrm{nmol} / \mathrm{l}$ and $8 \%$ at the level of $11 \mathrm{nmol} / \mathrm{l}$. For DHEAS, the detection limit was $0.2 \mu \mathrm{mol} / \mathrm{l}$. The intra-assay $\mathrm{CV}$ was $4 \%$ at the level of $6 \mu \mathrm{mol} / \mathrm{l}$ and $5 \%$ at the level of $20 \mu \mathrm{mol} / 1$, the interassay variation $8 \%$ at the level of $2.5 \mu \mathrm{mol} / 1$ and $6 \%$ at the level of $10 \mu \mathrm{mol} / \mathrm{l}$. Testosterone concentrations were determined using a double antibody radioimmunoassay (Coat-A-Count, DPC, Los Angeles, USA). The lower limit of detection was $0.3 \mathrm{nmol} / 1$; the intra-assay coefficient of variation was $12 \%$ at the level of $1.5 \mathrm{nmol} / \mathrm{l}$ and $4 \%$ at the level of $3 \mathrm{nmol} / \mathrm{l}$. The interassay coefficient of variation was $12 \%$ at the level of $2 \mathrm{nmol} / \mathrm{l}$.

\section{Ethical considerations}

The study was approved by the Committee on Ethics of Research involving Human Subjects of the Free University Hospital in Amsterdam. The adolescents were all under age. During the information meetings, it was clearly stated that the adolescents needed approval of their parents to participate in the study. They received an information letter to hand over to their parents. Parents gave informed consent by telephone or were present when the blood was taken. This policy was developed in collaboration with the Institutional Review Board.

\section{Statistics and assessment of reference values}

The gynaecological age (months) was calculated by subtracting the age at menarche (months) from the calendar age (months). For the statistical analysis, girls with secondary amenorrhoea were recorded as oligomenorrhoeic (Siegberg, 1987). The data were analysed with BMDP statistical software package (BMDP statistical software, Cork, Ireland). Within the regular menstrual cycle group a significant, 
Table II. Outline of the distribution of the source population made up of white, west European, ninth grade adolescents and their participation in blood sampling. Number of participants from source population excluded $=740$. Oral contraceptive users $(n=247)$, premenarche $(n=133),<6$ months postmenarche $(n=128)$, non-white, west European $(n=207)$, other reasons $(n=25)$

\begin{tabular}{lccc}
\hline Menstrual cycle pattern & $\begin{array}{l}\text { Total number } \\
\text { in subgroup }\end{array}$ & $\begin{array}{l}\text { Number with } \\
\text { blood sample }\end{array}$ & $\begin{array}{l}\text { Number with } \\
\text { blood sample } \\
\text { timed correctly } \\
\text { in cycle }\end{array}$ \\
\hline Regular menstrual cycles & 1394 & 110 & 107 \\
Polymenorrhoea & 17 & 10 & 10 \\
Oligomenorrhoea & 91 & 57 & 52 \\
Secondary amenorrhoea & 5 & 4 & 4 \\
Irregular menstrual cycles & 228 & 83 & 74 \\
\hline
\end{tabular}

positive correlation of gynaecological age with $\mathrm{LH}, \mathrm{FSH}$, testosterone, androstenedione and oestradiol was found. The mean hormone concentrations of girls with regular menstrual cycles versus those with other menstrual cycle patterns were compared by analysis of covariance to adjust for differences in gynaecological age between the various menstrual cycle pattern groups.

The 5th and 95th centiles of hormone concentrations adjusted for gynaecological age in girls with regular menstrual cycles were defined as the normal range. Values above the adjusted 95th centile of the regular menstrual cycle group were considered elevated. The normal range for body mass index by gynaecological age was determined with data from the 1394 girls with regular menstrual cycles (van Hooff et al., 1998a).

Logistic regression analysis was performed to calculate odds ratios adjusted for differences in gynaecological age of the proportions of girls in oligomenorrhoea, polymenorrhoea and the irregular menstrual cycle group with hormone levels above the 95th centile of the regular menstrual cycle group (Table V) or clinical characteristics of PCOS (Table IV). Logistic regression analysis was also used to estimate whether LH, testosterone, androstenedione and DHEAS contributed in an independent mode to discriminate between the oligomenorrhoeic group and the regular menstrual cycle group. $\chi^{2}$ analysis for linear trends was done to evaluate the increase in proportion of oligomenorrhoeic girls with high LH or androgen concentrations by gynaecological age.

\section{Results}

Table II shows the distribution of the respondents and the number of adolescents who participated in giving a blood sample classified by menstrual cycle pattern. In an earlier paper we described and discussed the relationship of the various menstrual cycle patterns with gynaecological age, body mass index and historical parameters (van Hooff et al., 1998a). For the present paper, we compared characteristics and answers to a questionnaire to determine whether adolescents who gave a blood sample were a representative sample of the menstrual cycle groups of which they were a member. No differences were found concerning age, body mass index, general health, use of medication, weight loss of $>5 \mathrm{~kg}$, subjective overweight, subjective hirsutism, duration of the period, and quantity of menstrual flow.

Girls with regular menstrual cycles who gave a blood sample had a higher gynaecological age and reported acne and dysmenorrhoea more frequently than the complete regular menstrual group [gynaecological age respectively $29.6 \pm 13.0$ months (mean $\pm \mathrm{SD}$ ) and 26.6 \pm 13.1 months, $t$-test $P=0.02$; acne 74 versus $61 \%, \chi^{2}$ test $P<0.01$; dysmenorrhoea 50 versus $37 \%, \chi^{2}$ test, $P=0.05$ ].

A greater number of girls with oligomenorrhoea, polymenorrhoea or irregular menstrual cycles who agreed to blood sampling reported participation in sports for $>8 \mathrm{~h}$ a week than girls without blood sampling $\left(\chi^{2}, P \leqslant 0.05\right)$. Girls from the irregular menstrual cycle group with blood sampling also reported nipple discharge and dysmenorrhoea more frequently ( $\chi^{2}$ test, $P=0.02$ and $P<0.01$ respectively). The mentioned $P$ values are not adjusted for multiple comparisons.

Adjustment in the analysis for differences in acne, dysmenorrhoea, participation in sports or nipple discharge by logistic regression did not change the results.

\section{Physical examination and hormone levels}

Table III shows a comparison of the mean hormone concentrations adjusted for gynaecological age between participants with regular menstrual cycles, oligomenorrhoea, polymenorrhoea or irregular menstrual cycles whose blood was sampled. LH, testosterone, androstenedione, DHEAS and oestradiol concentrations were significantly higher in oligomenorrhoeic girls than in girls with regular menstrual cycles. FSH and prolactin concentrations were higher in the polymenorrhoea group than in the regular menstrual cycle group. Mean LH, testosterone, DHEAS and prolactin concentrations were higher in the irregular menstrual cycle group than in the regular group. Table IV shows the proportion of girls with abnormal body hair, acne, and high or low body mass index. More oligomenorrhoeic girls had a Ferriman and Gallwey score $>1$ than those with regular menstrual cycles. Only seven girls had a Ferriman and Gallwey score $>8$. No relation between hirsutism and menstrual cycle pattern could be documented.

The proportion of participants in the oligomenorrhoea, polymenorrhoea and irregular menstrual cycle group who had hormone values above the 95th centile adjusted for gynaecological age of the regular menstrual cycle group is given in Table V. In particular, the proportion of oligomenorrhoeic girls with LH concentrations above the 95th centile is high, $45 \%$. Figure 1 shows the distribution of the individual values of LH in girls with regular menstrual cycles and oligomenorrhoea. Thirty-two (57\%) adolescents with oligomenorrhoea had a high LH or androgen value, or both. In the polymenorrhoea or the irregular menstrual cycle group, the proportion of adolescents with elevated hormone values of any hormone was not significantly higher than in the regular menstrual cycle group.

The proportion of adolescents with values below the 5th centile of the regular menstrual cycle group was low in girls with oligomenorrhoea, polymenorrhoea or irregular menstrual cycles. Only one girl with secondary amenorrhoea and none with another menstrual cycle pattern showed a hypogonadotrophic hypo-oestrogenic pattern.

The trend in relation to gynaecological age of oligomenorrhoeic girls with endocrine values above the 95th centile of the control group is shown in Table VI.

Multiple logistic regression showed that, adjusting for gynae- 
Table III. Hormone concentrations and body measurements (mean \pm SD) in adolescents with regular menstrual cycles, oligomenorrhoea, polymenorrhoea or irregular menstrual cycles, who agreed to blood sampling

\begin{tabular}{|c|c|c|c|c|}
\hline & $\begin{array}{l}\text { Regular menstrual cycles } \\
(n=107)\end{array}$ & $\begin{array}{l}\text { Oligomenorrhoea }^{\mathrm{a}} \\
(n=56)\end{array}$ & $\begin{array}{l}\text { Polymenorrhoea } \\
(n=10)\end{array}$ & $\begin{array}{l}\text { Irregular menstrual cycles } \\
(n=74)\end{array}$ \\
\hline Calender age (years) & $15.3 \pm 0.6$ & $15.8 \pm 0.5$ & $15.2 \pm 0.4$ & $15.2 \pm 0.5$ \\
\hline \multicolumn{5}{|l|}{ Adjusted hormone concentrations } \\
\hline Luteinizing hormone (IU/l) & $2.7 \pm 0.2$ & $5.6 \pm 0.3^{*}$ & $3.4 \pm 0.7$ & $3.3 \pm 0.2 * *$ \\
\hline Follicle stimulating hormone (IU/l) & $4.9 \pm 0.1$ & $4.7 \pm 0.2$ & $6.1 \pm 0.4 * *$ & $5.0 \pm 0.2$ \\
\hline Dehydroepiandrosterone sulphate $(\mu \mathrm{mol} / \mathrm{l})$ & $4.6 \pm 0.2$ & $5.4 \pm 0.3^{* *}$ & $5.1 \pm 0.7$ & $5.4 \pm 0.3^{* *}$ \\
\hline Oestradiol $(\mathrm{pmol} / \mathrm{l})$ & $121 \pm 7$ & $160 \pm 9^{*}$ & $108 \pm 21$ & $126 \pm 7$ \\
\hline Prolactin (IU/l) & $0.19 \pm 0.01$ & $0.19 \pm 0.01$ & $0.24 \pm 0.02 * * *$ & $0.22 \pm 0.01 * *$ \\
\hline \multicolumn{5}{|l|}{ Adjusted body measurements } \\
\hline BMI $\left(\mathrm{kg} / \mathrm{m}^{2}\right)$ & $20.4 \pm 0.3$ & $20.1 \pm 0.3$ & $20.6 \pm 0.8$ & $20.2 \pm 0.3$ \\
\hline
\end{tabular}

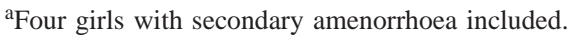

Student's $t$-test compared to regular menstrual cycle group in analysis of covariance $* P<0.001, * * 0.01<P<0.05$ and $* * * P=0.07$.

$\mathrm{BMI}=$ body mass index

Table IV. Odds ratio and 95\% confidence interval of the proportion adolescents with abnormal body hair, acne, underweight, or overweight in the oligomenorrhoea, polymenorrhoea or irregular menstrual cycles group compared to the regular menstrual cycles group

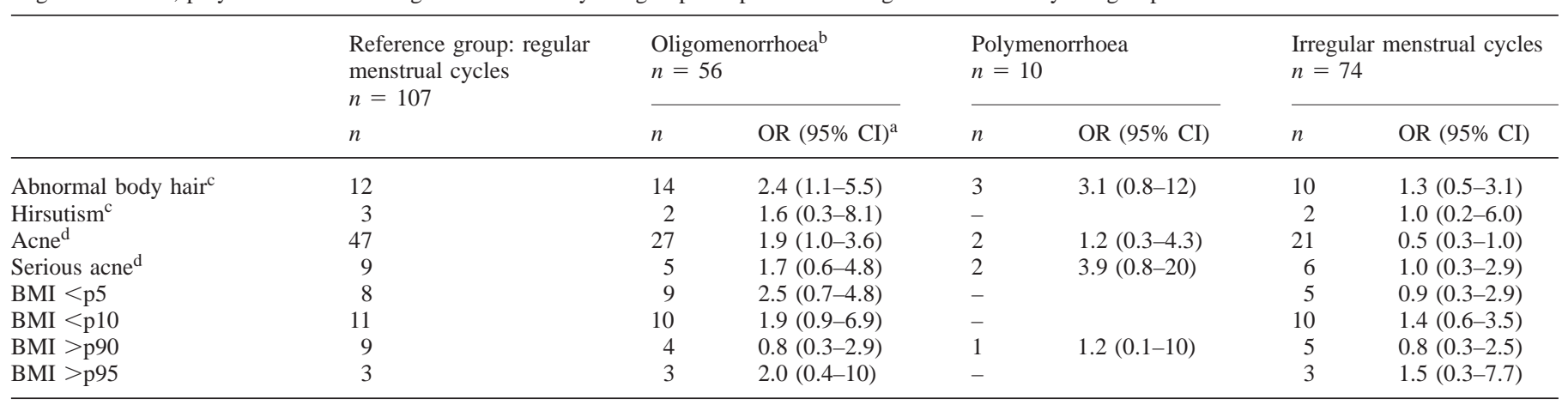

${ }^{\mathrm{a}} \mathrm{OR}(95 \% \mathrm{CI})=$ odds ratio and $95 \%$ confidence interval adjusted for gynaecological age calculated with logistic regression.

${ }^{\mathrm{b}}$ Four girls with secondary amenorrhoea included.

${ }^{c}$ Abnormal body hair: Ferriman and Gallwey score $>1$; hirsutism Ferriman and Gallwey score $>8$.

${ }^{\mathrm{d}}$ Acne: Plewig and Kligman score $>1$; serious acne: Plewig and Kligman score $>2$.

p5, p10, p90, p95 $=5$ th, 10th, 90th, 95th percentiles respectively.

$\mathrm{BMI}=$ body mass index

Table V. Proportion of adolescents in the oligomenorrhoea, polymenorrhoea or irregular menstrual cycle group with gonadotrophins, androgens, prolactin or oestradiol above the 95 th centile of the regular menstrual cycle group

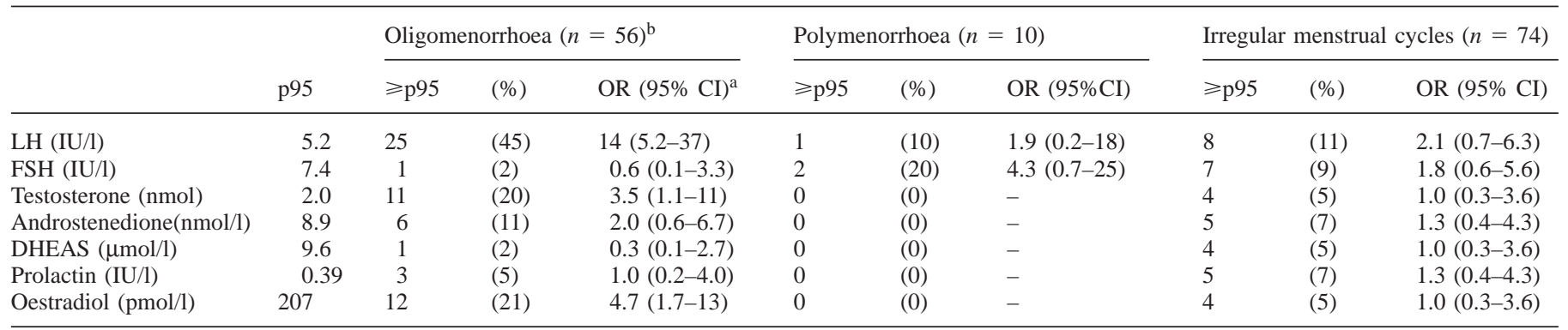

${ }^{a}$ Odds ratio and $95 \%$ confidence interval of proportion with hormone concentration above the 95 th centile of the regular menstrual cycle group. The regular menstrual cycle group is the reference category.

${ }^{\mathrm{b}}$ Four girls with secondary amenorrhoea included.

p95 = 95th percentile of regular menstrual cycle group; $\mathrm{LH}=$ luteinizing hormone, FSH $=$ follicle stimulating hormone; DHEAS $=$ dehydroepiandrosterone sulphate. 
cological age, LH and testosterone alone and used sequentially in any order contributed to the discrimination between individuals in the oligomenorrhoea and regular menstrual cycle groups. Androstenedione had no independent influence when LH or testosterone was adjusted for.

\section{Discussion}

This is the first report on endocrine measurements in an unselected population of adolescents classified by menstrual cycle pattern. The girls in our study are representative of the population of white, west European adolescent girls with the described menstrual patterns. The differences between girls who gave blood and who did not, had no major influence on the results as estimated with logistic regression. The endocrinology of the menstrual cycle during puberty in normal schoolgirls has been studied (Apter and Vihko, 1977). Although a distinction was made between ovulatory and anovulatory cycles, the authors did not mention the menstrual cycle pattern (Apter and Vihko, 1977; Apter, 1980). All other studies on the endocrinology of menstrual cycle disorders in adolescents have been performed in outpatient clinic populations (Emans et al., 1980; Singh, 1981; Moll and Rosenfield, 1983; Siegberg et al., 1986, 1987; Siegberg, 1987; Venturoli et al., 1987). It has been reported that only $39 \%$ of adults with secondary amenorrhoea consulted a doctor (Munster et al., 1992). This

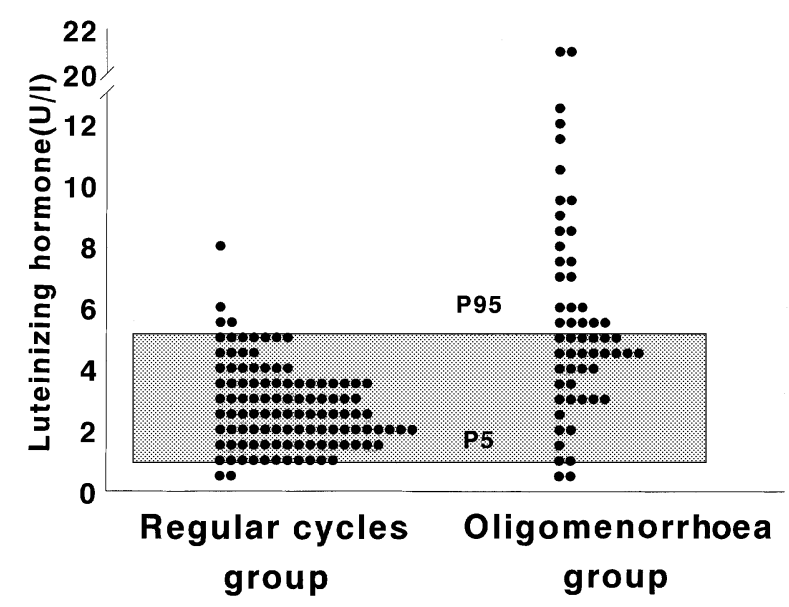

Figure 1. Distribution of luteinizing hormone concentrations adjusted for gynaecological age in adolescent girls with regular menstrual cycles $(n=107)$ and girls with oligomenorrhoea $(n=56)$. illustrates that selection bias may be involved in hospitalbased studies on this topic. In the present study, only one oligomenorrhoeic and one amenorrhoeic girl had consulted their physician about this menstrual cycle complaint before they participated in the study. Nine girls who used oral contraceptives reported they had been oligomenorrhoeic before they started to use the pill. These girls had also visited their physician, but in none had an endocrine evaluation been done before the pill was prescribed.

LH and androgens, the hormones that play a central role in the PCOS, were higher in the oligomenorrhoea group than in the regular menstrual cycle group. These findings agree with studies on the endocrinology of oligomenorrhoea and long cycles of girls with irregular menstrual cycles in outpatient clinic populations (Emans et al., 1980; Singh, 1981; Moll and Rosenfield, 1983; Siegberg, 1987; Venturoli et al., 1987).

Higher mean FSH and prolactin concentrations were found in polymenorrhoeic girls compared to those having regular menstrual cycles. The only other study on polymenorrhoea in adolescents found no endocrine difference between 13 polymenorrhoeic girls and 28 controls, except for a lower mean progesterone concentration during the luteal phase in polymenorrhoeic girls, due to a higher frequency of anovulatory cycles (Siegberg et al., 1987). Higher mean prolactin levels found in our polymenorrhoeic group may be explained by prolonged oestrogen stimulation in anovulatory subjects (Zacur and Foster, 1992). However, LH and androgen values were not high in this group, as might be expected in anovulatory subjects. A clear explanation for the higher mean FSH concentrations in the polymenorrhoeic girls cannot be given. Theoretically, high FSH concentrations may lead to a short follicular phase. This cannot be verified with our data. A negative correlation between FSH concentrations on days 34 of the cycle and the length of the follicular phase has been described (Apter and Vihko, 1985).

Except for the present study, only one report (Venturoli et al., 1985) has described the proportion of participants with hormonal values outside the normal range. They did not use adolescent controls, but adults who will have had higher hormone values than adolescents. In anovulatory cycles longer than 35 days, an LH concentration above the mean +2 SD of adult controls was found in six out of 20 adolescents $(30 \%)$ in the follicular phase around the fifth day of the cycle but in 14 out of $20(70 \%)$ adolescents during the premenstrual phase.

Table VI. Trends in relation to gynaecological age in proportion of oligoamenorrhoeic adolescents with luteinizing hormone and androgen concentrations above the 95th percentile levels of the regular menstrual cycle group

\begin{tabular}{|c|c|c|c|c|c|}
\hline & \multicolumn{5}{|c|}{ Gynaecological age (months) } \\
\hline & $\begin{array}{l}6-11 \\
n=8\end{array}$ & $\begin{array}{l}12-23 \\
n=22\end{array}$ & $\begin{array}{l}24-35 \\
n=17\end{array}$ & $\begin{array}{l}\geqslant 36 \\
n=9\end{array}$ & $\begin{array}{l}\chi^{2} \text { for } \\
\text { linear trend }\end{array}$ \\
\hline LH (IU/l) & $2(25 \%)$ & $10(45 \%)$ & $7(41 \%)$ & $6(67 \%)$ & $P=0.15$ \\
\hline Testosterone (nmol/l) & $1(13 \%)$ & $6(27 \%)$ & $3(18 \%)$ & $1(11 \%)$ & $P=0.60$ \\
\hline Androstenedione (nmol/1) & $0(0 \%)$ & $3(14 \%)$ & $1(6 \%)$ & $2(22 \%)$ & $P=0.30$ \\
\hline LH and androgens combined & $3(37 \%)$ & $14(64 \%)$ & $9(53 \%)$ & $6(67 \%)$ & $P=0.50$ \\
\hline
\end{tabular}

Values in parentheses are percentages. 
This illustrates an effect of timing of blood sampling on hormone values in the oligomenorrhoeic cycle. In oligomenorrhoeic girls, we took blood samples at least 2 weeks after the first day of a menstruation and at least 3 weeks before the next, according to the concept of the specific oligomenorrhoeic phase (see Materials and methods). The rules we followed exclude the influence of peri- and postovulatory hormonal changes which also effect the hormone concentration in the first 2 weeks of the next menstrual cycle (Minakami et al., 1988; van Hooff et al., 1998b). We did not document ovulation in the study cycle.

Although significant differences in mean weight, body mass index, and waist circumference were documented between oligomenorrhoeic girls with and without endocrine signs of PCOS, the proportion of girls with obesity, acne or hirsutism was comparable in these subgroups (data not shown). In our study, these physical characteristics had no value in discriminating between oligomenorrhoeic girls with or without endocrine abnormalities.

The proportion of oligomenorrhoeic girls with high LH or androgen values, or both, appeared to increase in relation to gynaecological age, but the trend was not significant. Nearly $60 \%$ of the oligomenorrhoeic girls have endocrine signs compatible with PCOS in adults. A high LH value is the most frequent abnormality in oligomenorrhoeic adolescents.

Girls with irregular menstrual cycles also had higher mean LH, testosterone, DHEAS and prolactin concentrations. The differences between the irregular and regular menstrual cycle group were small in contrast to the differences between the oligomenorrhoea and regular menstrual cycle group. Moreover, the proportion of individuals with high concentrations was not increased in the irregular menstrual cycle group. Crosssectional data from the POMP study showed that the prevalence of irregular menstrual cycles significantly decreased with increasing gynaecological age (van Hooff et al., 1998a). The prevalence of oligomenorrhoea showed no significant decrease. These findings may be in accordance with the hypothesis that high LH and androgen concentrations in adolescents with irregular menstrual cycles are a functional step of maturation of the ovulatory system (Apter, 1980; Venturoli et al., 1985), but that high concentrations of these hormones in oligomenorrhoeic girls are not transient and may be an early sign of PCOS.

The implications of endocrine abnormalities in our random population sample of oligomenorrhoeic adolescents are not clear. However, results of earlier studies suggest that most adolescents with oligomenorrhoea continue to have this menstrual cycle pattern combined with subfertility in adulthood (Southam and Richart, 1966; Kimura et al., 1988; Apter and Vihko, 1990). It was shown (Southam and Richart, 1966) that $60 \%$ of adolescent patients, who had oligomenorrhoea 2 years after menarche kept this pattern in the following 8 years. In one study (Kimura et al., 1988), it was found that the majority of 17 adolescent patients with menstrual cycle disorders and high LH concentrations suffered from ovulatory disturbance in adulthood. It has been shown (Apter and Vikho, 1990) that adolescent serum testosterone and androstenedione concentrations are preserved into adulthood and are reflected in fertility patterns during the third decade of life. Higher serum androgen concentrations were associated with lower fertility. No cut-off level for individuals with a high chance for fertility problems was given.

Two studies (Singh, 1981; Gardner, 1983) reported that doctors tend to reassure adolescents that their menstrual pattern disorder will be transient and is due to incomplete maturation of the hypothalamic-pituitary-ovarian axis. Our study and other studies suggest that oligomenorrhoea in adolescents is not a transient stage in the physiological maturation of the hypothalamic-pituitary-ovarian axis but an early sign of PCOS. Endocrine evaluation should be considered before reassuring oligomenorrhoeic adolescents or prescribing oral contraceptives to these girls.

\section{Acknowledgements}

We are indebted to the girls and the management of the schools that participated in the study. We thank the staff of the endocrine laboratory of Vrije Universiteit Medical Centre (head Dr C. Popp-Snijders) for performing the hormone determinations. This study was funded by the Pubertal onset of Menstrual cycle abnormalities: a Prospective study was financially supported by Wyeth Lederle, the Netherlands and the Dutch Prevention Fund (project 28-2176).

\section{References}

Apter, D. (1980) Serum steroids and pituitary hormones in female puberty: a partly longitudinal study. Clin. Endocrinol., 12, 107-120.

Apter, D. and Vihko, R. (1977) Serum pregnenolone, progesterone, 17hydroxyprogesterone, testosterone and 5-alpha-dihydrotestosterone during female puberty. J. Clin. Endocrinol. Metab., 45, 1039-1048.

Apter, D. and Vihko, R. (1985) Hormonal patterns of the first menstrual cycles. In Venturoli, S., Flamigni, C. and Givens, J. (eds), Adolescence in Females. Year Book Medical Publishers, Chicago.

Apter, D. and Vihko, R. (1990) Endocrine determinants of fertility: serum androgen concentrations during follow-up of adolescents into the third decade of life. J. Clin. Endocrinol. Metab., 71, 970-974.

Emans, S.J., Grace, E. and Goldstein, D.P. (1980) Oligomenorrhoea in adolescent girls. J. Pediatr., 97, 815-819.

Ferriman, D. and Gallwey, J.D. (1961) Clinical assessment of body hair growth in women. J. Clin. Endocrinol. Metab., 21, 1440-1447.

Fletcher, R.H., Fletcher, S.W. and Wagner, E.H. (1988) Clinical Epidemiology. The Essentials, 2nd edition. Williams \& Wilkins, Baltimore, pp. 58-61.

Gardner, J. (1983) Adolescent menstrual characteristics as predictors of gynaecological health. Ann. Hum. Biol., 10, 31-40.

Kimura, K., Minakami, H., and Tamada, T. (1988) [A longitudinal study on the prognosis of ovulatory disturbance in teenage patients with high LH and normal FSH serum levels]. Nippon Naibunpi Gakkai Zasshi., 64, 1088-1101.

Minakami, H., Abe, N., Izumi, A., and Tamada, T. (1988) Serum luteinizing hormone profile during the menstrual cycle in polycystic ovarian syndrome. Fertil. Steril., 50, 990-992.

Moll, G.W. Jr and Rosenfield, R.L. (1983) Plasma free testosterone in the diagnosis of adolescent polycystic ovary syndrome. J. Pediatr., 102, 461-464.

Munster, K., Helm, P. and Schmidt, L. (1992) Secondary amenorrhoea: prevalence and medical contact - a cross-sectional study from a Danish county. Br. J. Obstet. Gynaecol., 99, 430-433.

Plewig, G. and Kligman, A.M. (1975) Acne Morphogenesis and Treatment. Springer-Verlag, Berlin.

Roede, M.J. and Van Wieringen, J.C. (1985) Growth diagrams 1980: Netherlands third nation wide survey. Tijds. Soc. Geneesk., 63, 1-34 (supplement).

Sackett, D.L., Haynes, R.B., Guyatt, G.H. and Tugwell, P. (1991) Clinical Epidemiology. A Basic Science For Clinical Medicine, 2nd edition. Little, Brown and Company, Boston, pp. 178-180.

Siegberg, R. (1987) Serum sex hormone concentrations in adolescent secondary amenorrhoea. Ann. Chir. Gynaecol., 76, 176-180. 
Siegberg, R., Nilsson, C.G., Stenman, U.H. and Widholm, O. (1986) Endocrinologic features of oligomenorrhoeic adolescent girls. Fertil. Steril., 46, 852-857.

Siegberg, R., Nilsson, C.G., Stenman, U.H., and Widholm, O. (1987) Serum sex hormone levels in adolescent girls with polymenorrhoea. Ann. Clin. Res., 19, 183-186.

Singh, K.B. (1981) Menstrual disorders in college students. Am. J. Obstet. Gynecol., 140, 299-302.

Southam, A.L. and Richart, R.M. (1966) The prognosis for adolescents with menstrual abnormalities. Am. J. Obstet. Gynecol., 94, 637-645.

Tanner, J.M. (1962) Growth at Adolescence. Blackwell Scientific Publications, Oxford.

van Hooff, M.H.A., Voorhorst, F.J., Kaptein, M.B.M. et al. (1998a) Relationship of the menstrual cycle pattern in 14-17 year old adolescents with gynaecological age, body mass index and historical parameters. Hum. Reprod., 13, 2252-2260.

van Hooff, M.H.A., van der Meer, M., Lambalk, C.B. and Schoemaker, J. (1998b) Effect of timing of bloodsampling for LH determination on the detection of elevated LH levels in oligomenorrhoeic women. Fertil. Steril., Supplement IFFS '98: S210(Abstract).

Venturoli, S., Porcu, E., Fabbri, R. et al. (1985) Endocrine profiles and ovarian aspects in adolescent menstrual abnormalities. In Venturoli, S., Flamigni, C. and Givens, J. (eds), Adolescence in Females. Year Book Medical Publishers, Chicago.

Venturoli, S., Porcu, E., Fabbri, R. et al. (1987) Postmenarchal evolution of endocrine pattern and ovarian aspects in adolescents with menstrual irregularities. Fertil. Steril., 48, 78-85.

Westrate, J.A., Deurenberg, J. and Van Tinteren, H. (1989) Indices of body fat distribution and adiposity in Dutch children from birth to 18 years of age. Int. J. Obesity, 13, 465-477.

Zacur, H.A. and Foster, G.V. (1992) Hyperprolactinemia and polycystic ovarian syndrome. Semin. Reprod. Endocrinol., 10, 236-245.

Received on December 15, 1998; accepted on May 24, 1999 